\title{
Cigarette smoking among university students in Greece: a comparison between medical and other students
}

\author{
Evangelos C. Alexopoulos · Eleni Jelastopulu • \\ Konstantinos Aronis · Dimitris Dougenis
}

Received: 10 July 2009/Accepted: 4 September 2009/Published online: 3 October 2009

(C) The Japanese Society for Hygiene 2009

\begin{abstract}
Objectives The purpose of the study was to investigate the smoking habits of medical and other students and to explore the most important factors associated with students' smoking.

Methods University students were surveyed in late spring 2006 regarding their smoking status and additional healthand behavior-related characteristics.

Results A total of 1205 (269 medical and 936 nonmedical) students participated in the study. Of these $47 \%$ reported being current smokers $(35 \%$ among medical students), and $30 \%$ of the smokers had already started smoking at the age of 16 years. Smokers reported a significantly higher prevalence of cough and respiratory infections and a decrease in physical fitness. The most important factor associated with smoking prevalence was friendship with smokers and maternal smoking. A better knowledge of harmful effects showed a strong association with nonsmokers. Although nonmedical students exhibited a greater possibility to be a smoker, awareness of harmful effects among medical students was not as significant as factor against smoking compared with among nonmedical students.
\end{abstract}

E. C. Alexopoulos and E. Jelastopulu contributed equally and share first authorship.

E. C. Alexopoulos $(\bowtie) \cdot$ E. Jelastopulu $\cdot$ K. Aronis

Department of Public Health, Medical School,

University of Patras, 26500 Rio Patras, Greece

e-mail: ecalexop@upatras.gr

D. Dougenis

Department of Cardiothoracic Surgery,

Medical School, University of Patras,

Rio Patras, Greece
Conclusions This study shows that smoking prevalence among medical and other students in Greece is extremely high. A lack of effective education against smoking in medical students was evident and this underlines the need to identify the factors to be included in planning effective antismoking programs.

Keywords University - Smoking - Prevalence ·

Risk awareness · Students · Medical students - Education

\section{Introduction}

Smoking is a major public health problem throughout the world. It constitutes the single leading cause of preventable death and disease [1] and, according to the World Health Organization (WHO), 5.4 million die every year from tobacco [2]. Among European countries, Greece ranks first in cigarette consumption per person [2], not only in general but also in regard to student smoking [3].

Since most smokers start smoking before high-school graduation or immediately after, students should be considered a primary target for tobacco prevention programs. The university years provide an opportunity for interventions to prevent future premature morbidity and mortality by discouraging initiation or continuation of harmful health-related behaviors such as tobacco use [3-7]. Smoking prevention programs have been given high priority in WHO policies. It is of great importance that universities implement in their curricula intervention and awareness programs in order to address this huge public health problem.

In Greece, studies of smoking habits in youths and students are scarce, especially among nonmedical university students. A review article published in 2007 pointed 
out seven population-based epidemiological studies in the time period 2000-2006 regarding the smoking habits of high-school and university students [8]. According to these studies, smoking prevalence among high-school students ranged from $10 \%$ to $32 \%$ for 15 -year-old to a maximum of $50 \%$ for 16 - to 19 -year-old students [8-11].

The purpose of this study was to determine the prevalence of smoking and to investigate the smoking habits of medical and other students enrolled in a major university in Greece using a cross-sectional survey approach. Further interest was to explore the patterns of smoking across schools and academic years, and to identify the most important factors related to students' smoking.

\section{Materials and methods}

\section{Setting}

A cross-sectional study was conducted at Patras University, a public self-administered academic institution under the supervision of the Greek Government, during the summer semester of 2006. The university consists of four schools including 22 departments [12]. All schools are fully accredited for their education programs and enroll students mainly from Greece and Cyprus. A total of 20069 (55\% males) were enrolled in the university at the time of the study (summer semester 2006).

\section{Sampling procedure and data collection}

All schools were selected to be surveyed, and administrators at each department were asked to provide the total enrollment of undergraduate students. The study was designed to include more than 1000 students ( $~ 5 \%$ of all enrolled students at the university). Systematic steps were taken to ensure that the relative proportions of students were equivalent between departments, except for the medical school where a fivefold probability, proportionate to size, sampling compared with other departments was used. Finally $4.93 \%$ of all nonmedical $(n=18971)$ and $24.5 \%$ of medical students $(n=1098)$ participated in the study.

Under a cross-sectional design, students were surveyed on May 2006 using a self-administered anonymous questionnaire. The 17-item questionnaire was handed over to students during the period of university elections when most of the students were on campus locations. Attempts were made to survey all available students without using any randomization schemes.

To avoid duplicate responses, specific instructions were provided at the beginning of the survey to complete the questionnaire only once and to disregard the survey if they had previously participated in the study. No incentives were provided for participation in the study and no individual follow-up was possible. All available students were asked to complete an anonymous questionnaire and some were interviewed, if they wished to. The response rate exceeded $80 \%$. The questionnaires were distributed to them by a team of medical students and were returned to them after completion, which required $<10 \mathrm{~min}$. Survey procedures were designed to protect students' privacy by allowing for anonymous and voluntary participation without external pressure.

The anonymous questionnaire was developed by the authors and pretested on a group of students prior to initiation of the survey and revised. Demographic characteristics included age, sex, height, and weight with additional information regarding academic year/semester. Validation of the responses by objective means was not undertaken. The questionnaire was approved by the Board of Medical School and the Dean of the University of Patras.

Smoking status was established in accordance with WHO criteria [1]: smokers were subjects who, at the time of the study, smoked either daily (at least 1 cigarette per day) or occasionally ( $<1$ cigarette per day); smokers also included experimenters, namely those who were smoking during this survey but had smoked fewer than 100 cigarettes in their lifetime. Nonsmokers included subjects who, at the time of the survey, did not smoke, such as exsmokers and never-smokers. Ex-smokers were formerly smokers, but currently did not smoke at all; never-smokers did not smoke at all or had smoked fewer than 100 cigarettes in their lifetime, but at the time and for the month before the survey they were not smoking. Smokers were asked about the average number of cigarettes smoked daily and about the age of initiation as well as about their attempts to quit, if any. Data on the smoking status of parents and friends, beliefs about smoking, knowledge/ awareness of harmfulness of smoking, frequency of infections of the upper respiratory tract in the last 12 months and possible hospitalization due to these, cough, frequency of physical exercise, and decrease in physical fitness were also collected.

Statistical analysis

SPSS software version 15.0 was used to calculate the frequencies of each variable. Pearson chi-square test was used for comparing proportions, and Student's $t$ test was used to compare the difference in means. Logistic regression analyses were used to test the relation between smoking and the different demographic and health risk behavioral characteristics. Adjusted odds ratios (ORs) and 95\% confidence intervals (95\% CIs) are reported. 


\section{Results}

A total of 1205 questionnaires were collected, 269 from medical students and 936 from nonmedical students (Table 1). The sample included more females (54.3\%) than males $(45.7 \%)$. Respondents' age ranged from 18 to 35 years, with a median age of 20 years (mean 20.6 years, SD 1.93 years). Men exhibited a significant higher body mass index (BMI) compared with women, with 141 $(26.1 \%)$ classified as overweight $\left(25 \mathrm{~kg} / \mathrm{m}^{2}<\mathrm{BMI} \leq\right.$ $\left.30 \mathrm{~kg} / \mathrm{m}^{2}\right)$ and $14(2.6 \%)$ as obese $\left(\mathrm{BMI}>30 \mathrm{~kg} / \mathrm{m}^{2}\right)$ compared with $3.1 \%$ and $0.2 \%$ of women, respectively (Table 1). There was no significant difference in distribution of age, gender, and year of education between medical and nonmedical students.

Of the participants $46.9 \%$ were current smokers. Current smokers included light smokers ( $<10$ cigarettes per day; $35 \%$ ), medium smokers (10-19 cigarettes per day; 37.6\%), and heavy smokers ( $\geq 20$ cigarettes per day; 27.4\%). Around $60 \%$ in the category of light smokers were occasionally smokers, i.e., they smoked $<7$ cigarettes per week. More than 50\% (292) of smoking students started smoking

Table 1 Individual characteristics of the study population

\begin{tabular}{|c|c|c|}
\hline & $\begin{array}{l}\text { Males } \\
n=551\end{array}$ & $\begin{array}{l}\text { Females } \\
n=654\end{array}$ \\
\hline Age [years, mean $(\mathrm{SD})]^{*}$ & $20.98(2.09)$ & $20.35(1.74)$ \\
\hline Height $[\mathrm{cm} \text {, mean }(\mathrm{SD})]^{*}$ & $179.75(9.93)$ & $166.80(5.58)$ \\
\hline $\begin{array}{l}\text { BMI (body mass index) } \\
{\left[\mathrm{kg} / \mathrm{m}^{2}, \text { mean }(\mathrm{SD})\right]^{*}}\end{array}$ & $23.99(2.73)$ & $20.57(2.21)$ \\
\hline \multicolumn{3}{|l|}{ Year of education $[n(\%)]^{*}$} \\
\hline 1 st and 2 nd & $219(39.8)$ & $316(48.3)$ \\
\hline $3 r d$ & $144(26.1)$ & $181(27.7)$ \\
\hline 4th and over & $188(34.1)$ & $157(24)$ \\
\hline \multicolumn{3}{|l|}{ Physical exercise* } \\
\hline Less than $2 \mathrm{~h}$ weekly & $246(44.6)$ & $390(59.6)$ \\
\hline 3-7 h weekly & $194(35.2)$ & $195(29.8)$ \\
\hline More than $1 \mathrm{~h}$ daily & $103(18.7)$ & $40(6.1)$ \\
\hline \multicolumn{3}{|l|}{ Smoking status $[n(\%)]^{*}$} \\
\hline Nonsmoker & $272(49.4)$ & $368(56.3)$ \\
\hline Current & $279(50.6)$ & $286(43.7)$ \\
\hline$<10$ cigarettes daily & $78(14.2)$ & $106(16.2)$ \\
\hline 10-19 cigarettes daily & $98(17.8)$ & $100(15.3)$ \\
\hline$\geq 20$ cigarettes daily & $83(15.1)$ & $62(9.5)$ \\
\hline \multicolumn{3}{|l|}{$\begin{array}{l}\text { Age of starting smoking } \\
\text { [years, } n(\%)]\end{array}$} \\
\hline$\leq 14$ & $16(2.9)$ & $17(2.6)$ \\
\hline $15-16$ & $57(10.3)$ & $58(8.9)$ \\
\hline $17-18$ & $110(20)$ & $106(16.2)$ \\
\hline
\end{tabular}

$* p<0.05$ after entering the university, whereas $47 \%$ (264) started earlier ( 9 did not answer). Among those who started earlier two-thirds $(65 \%)$ had already started smoking at the age of 16 years, while $7.2 \%$ started even before the age of 14 years. Of the students who started smoking after entering the university more than $60 \%$ where younger than 19 years (i.e., smoking onset was in the first academic year). At the age of 21 years almost all smoking students had already started to smoke.

Of the medical students $35.3 \%$ were smokers, compared with $50.2 \%$ (470/936) smokers among nonmedical students. Smoking prevalence was about $53 \%$ in the school of economics and management as well as in the school of natural sciences, while it was lower (48\%) in the school of humanities and social sciences and the school of engineering; these differences were not statistically significant. Smoking prevalence increased with age and year of education. Among students of the first two study years prevalence of smoking was $43.7 \%$, whereas among senior students (4th year and higher) it was more than $50 \%$. Figure 1 shows the percentage of current smokers by school, gender, and academic year. It seems that the prevalence of smoking increases with the year of education for both males and females; however, this trend is not quite as evident for nonmedical students, especially for males (Fig. 1).

About $44 \%$ of current smokers amongst medical students reported at least one attempt to quit, compared with $36 \%$ of smoking students from other schools. This difference did not reach statistical significant level $(p=0.154)$.

Smoking was significantly higher among students whose mothers were smokers, those having smoker friends, and those being less aware of the detrimental health effects of smoking (Table 2). Smoking students reported three times more suffering from cough and five times more perceiving a decrease in physical fitness. Infections of the respiratory tract showed a significant positive correlation with smoking (Table 2). It is worth mentioning that occasional smokers reported comparable frequencies to nonsmokers regarding cough, whereas physical fitness deterioration and frequency of respiratory infections were similar to those of regular smokers.

The factors associated significantly with smoking in the overall study population are shown in Table 3. Although the age range in this study was limited there was a positive association with smoking (OR 1.15, 95\% CI 1.08-1.23). Nonmedical students exhibited a higher possibility to be a smoker (OR 1.77, 95\% CI 1.30-2.43). The most important factors associated with smoking prevalence seem to be friendship with smokers (OR 3.49, 95\% CI 2.50-4.87) and maternal smoking (OR 1.44, 95\% CI 1.11-1.87). A better knowledge of harmful effects is strongly associated with nonsmoking (OR 0.27, 95\% CI 0.14-0.53). However, 


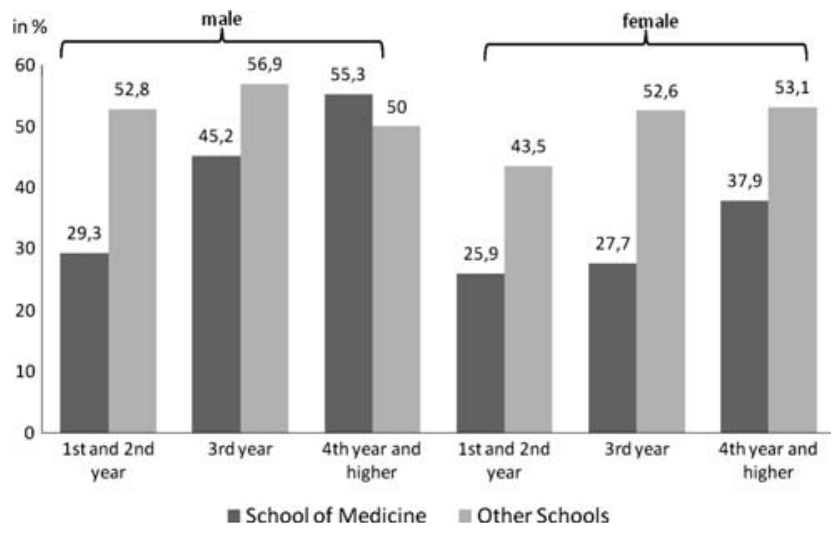

Fig. 1 Smoking prevalence (\%) by school, gender, and year of education among Greek university students $(n=1205)$

Table 2 Characteristics associated with smoking in university students $(n=1205)$

$\begin{array}{ll}\text { Nonsmokers } & \text { Current } \\ n=640 & \text { smokers } \\ (\%) & n=565\end{array}$

$(\%)$

\begin{tabular}{lcc}
\hline Parental smoking & & \\
$\quad$ Father smoker & $301(47.6)$ & $288(51.6)$ \\
$\quad$ Mother smoker* & $180(29.1)$ & $209(38.3)$ \\
$\begin{array}{l}\text { Family history of cancer } \\
\text { related to smoking }\end{array}$ & $24(4.5)$ \\
Fiends smokers* & $437(69.7)$ & $500(89.4)$ \\
Knowledge/awareness & $622(98)$ & $524(92.7)$ \\
$\quad$ of harmfulness* & & \\
Physical exercise* & $300(49.7)$ & $336(59.6)$ \\
$\quad$ None or $<2$ h weekly & $208(34.4)$ & $181(32.1)$ \\
$\quad$ Medium (3-7 h weekly) & $96(15.9)$ & $47(8.3)$ \\
$\quad$ Heavy (more than 1 h daily) & $81(16.4)$ & $286(51)$ \\
Cough* & $76(14.7)$ & $385(68.5)$ \\
Decrease of physical fitness* & $48(8.4)$ & $68(12.5)$ \\
Respiratory infections $\geq 2$ & $11(2)$ & $17(3.1)$ \\
times last year & & \\
Hospitalizations due to respiratory \\
infections
\end{tabular}

analyzing medical and nonmedical students separately, better knowledge of harmful effects seems to be far less important for medical students (OR 0.55, 95\% CI 0.122.44) compared with nonmedical students (OR $0.23,95 \%$ CI 0.10-0.50). In addition, seniority (4th year and higher compared with the first two study years) was associated with a decreased possibility of smoking (OR $0.53,95 \% \mathrm{CI}$ $0.32-0.88)$, but only among nonmedical students.
Table 3 Significant factors associated with smoking status among university students $(n=1205)$

\begin{tabular}{|c|c|c|c|c|}
\hline & \multicolumn{2}{|c|}{ Unadjusted } & \multicolumn{2}{|c|}{$\begin{array}{l}\text { Adjusted } \\
\text { for the } \\
\text { final model }\end{array}$} \\
\hline & OR & $95 \% \mathrm{CI}$ & OR & $95 \% \mathrm{CI}$ \\
\hline Age (in years) & 1.12 & $1.06-1.19$ & $1.15^{\mathrm{a}}$ & $1.08-1.23$ \\
\hline Mother smoker & 1.51 & $1.19-1.93$ & $1.44^{\mathrm{a}}$ & $1.11-1.87$ \\
\hline Fiends smokers & 3.69 & $2.68-5.07$ & $3.49^{\mathrm{a}}$ & $2.50-4.87$ \\
\hline Knowledge of harm & 0.27 & $0.14-0.50$ & $0.27^{\mathrm{a}}$ & $0.14-0.53$ \\
\hline \multicolumn{5}{|l|}{ Faculty (school) } \\
\hline School of Health Sciences & 1 & & $1^{\mathrm{a}}$ & \\
\hline Other schools & 1.85 & $1.40-2.45$ & 1.77 & $1.30-2.43$ \\
\hline \multicolumn{5}{|l|}{ Year of education $[n(\%)]$} \\
\hline 1 st and 2 nd & 1 & & 1 & \\
\hline $3 r d$ & 1.19 & $0.90-1.57$ & 0.99 & $0.70-1.38$ \\
\hline 4th and higher & 1.32 & $1.01-1.74$ & 0.64 & $0.41-1.01$ \\
\hline Males & 1.32 & $1.05-1.66$ & NS & \\
\hline $\begin{array}{l}\text { Body mass index } \\
\text { (BMI) }\left(\mathrm{kg} / \mathrm{m}^{2}\right)\end{array}$ & 1.05 & $1.01-1.09$ & NS & \\
\hline Father smoker & 1.17 & $0.93-1.47$ & NS & \\
\hline
\end{tabular}

$N S$ No significance $(p>0.15)$

${ }^{\text {a }}$ Covariates of the final model

\section{Discussion}

Major findings of this study

We have conducted a smoking survey in a Greek university, a country with the highest per-capita consumption of cigarettes among European Union member states. The study group consisted of junior and senior students of the University of Patras, the third largest in Greece. The prevalence rates were $26-56 \%$ for medical and $44-57 \%$ for nonmedical students, depending on gender and year of education. Moreover, our results suggest that medical education had little effect on students' decisions against smoking.

What is already known on this topic

Several studies have shown declining trends, especially among medical students with prevalence rates $<20 \%$, while other studies reported high tobacco consumption among medical students and even higher (up to 47\%) among other nonmedical students [13-15].

Studies up to now have tended to survey medical students alone or rather have failed to differentiate between medical and other students [15-17]. In contrast to a Chinese survey we found significant differences between medical and nonmedical students regarding smoking 
prevalence rates, although these differences become smaller with more years of education. Similar increasing trends of smoking among medical students are shown in other studies [18, 19]. However, due to the cross-sectional design of our study, the actual situation may not be truly reflected, i.e., the riskiest period for starting smoking [20].

Although this cross-sectional design is not adequate to elucidate the timing of adoption of smoking behavior, the analysis indicated that every 2 years a significant proportion of students (around 10\%) become smokers. The prevalence of smokers found in our study population in the ages up to 16 years $(14.1 \%)$ was comparable to that in other reports $[2,21]$, while at the ages of $17-18$ years the corresponding prevalence was lower in our study $(22 \%$ versus $36 \%$ ), thus possibly indicating a selective subpopulation among all adolescents. In our research the riskiest period for initiation of smoking among university students seems to be the first year of education. Actually, one would expect that, with each year of medical education, more students would realize the adverse effects of smoking not only on their own health, but also on the health of people they have to care for. It seems that medical education does not have preventative effects, or rather does not influence the smoking attitudes and behaviors of the students. A complex set of reasons is implicated in this paradox, which requires further exploration [22].

More important is that physicians are expected to play an important role in the campaign against smoking, which means not only to advice their patients but to set an example for them. The time during education seems to be the ideal period to embed such a positive influence. It is anticipated that medical schools should teach the health hazards of tobacco use and train students in specific smoking cessation techniques. There were strong negative associations between smoking and beliefs in the importance for health of not smoking. This was mainly obvious for nonmedical students. In fact, inadequate undergraduate education about tobacco-related health risks has been reported to be one of the many factors that may contribute to missed opportunities $[14,23]$. It might be of importance to include antismoking education in the curricula of all medical and nonmedical schools but not in a superficial way.

Even though parental smoking patterns and attitudes are well known to affect child smoking [24], in our research only mothers' smoking habits exhibited a very strong relation, especially for those started smoking before university entrance. Higher prevalence of detrimental effects among young smokers has also been reported [25].

The high proportion of students who started smoking prior to age 16 or even 14 years confirms that early tobacco initiation continues to be a serious problem in Greece. It is interesting to note in this context that no ban on tobacco sales to people $<18$ years of age exists in Greek legislation, although there are laws and regulations concerning strict limitations on tobacco advertising, warning labels on tobacco packages, and the very recent ban on smoking in all workplaces and in public and private facilities. There are also ministerial guidelines for school smoking concerning the prevention and proper counseling of young smokers by teachers, but generally all of these policies have proven to be ineffective.

\section{What this study adds}

This study shows an extremely high prevalence of smoking among medical and other students in Greece and that medical studies are not effective in reducing tobacco use. This underlines the need to monitor trends in tobacco consumption, ascertain factors affecting the decision to smoke, and identify cultural factors influencing a nonsmoking choice in order to plan effective preventive strategies.

This research underlines the need to collect basic information about tobacco smoking among students, prior to implementation of new curricula, since the approach and credibility of provision might vary. Additionally, the information on possible differences in smoking habits between students may help to improve and target educational programs on promoting undergraduate education in smoking cessation [23].

Limitations of this study

Our results are based on a survey in a major university in Greece and are not necessarily representative either of the University of Patras or of the student population of the entire country. However, compared with similar studies in university settings, the sample was larger and randomly selected per school; hence selection bias is unlikely to have occurred. Furthermore, as a cross-sectional survey no causal inference is possible in this study. An additional issue is the definition of smoking. In our definition we did not treat occasional smokers separately, which might be deficient for describing smoking behavior. Occasional smokers were treated as smokers, but they may feature differences as other studies have shown [26]. This study may not be necessarily representative of young adults since a socioeconomic gradient between university students and the general population is anticipated, and higher tobacco use in less privileged and less educated groups has been reported [27, 28].

Acknowledgments We would like to thank the senior medical students (now physicians): Konstantinos Dimitropoulos, Evangelos Georgiou, Vassilios Lazaris, and Charalambos Vitsas for data 
collection and preparation. Furthermore we would like to thank the students of the University of Patras for their participation in this research.

\section{References}

1. World Health Organization (WHO): Facts and figures about tobacco. http://www.who.int/tobacco/fctc/cop/en/index.html (2006). Accessed 21 May 2009.

2. World Health Organization. WHO Report on the Global Tobacco Epidemic, 2008: the MPOWER package. Geneva: World Health Organization; 2008.

3. Steptoe A, Wardle J, Cui W, et al. An international comparison of tobacco smoking, beliefs and risk awareness in university students from 23 countries. Addiction. 2002;97:1561-71.

4. Rundall TG, Bruvold WH. A meta-analysis of school-based smoking and alcohol use prevention programs. Health Educ. 1988;15:317-34.

5. Morrell HE, Cohen LM, Dempsey JP. Smoking prevalence and awareness among undergraduate and health care students. Am J Addict. 2008;17:181-6.

6. Saleiro S, Damas C, Gomes I. Smoking habits and awareness of smoking risks depending on academic background in university students. Rev Port Pneumol. 2008;14:231-8.

7. Thyrian JR, Panagiotakos DB, Polychronopoulos E, West R, Zatonski W, John U. The relationship between smokers' motivation to quit and intensity of tobacco control at the population level: a comparison of five European countries. BMC Public Health. 2008;8:2.

8. Vardavas CI, Kafatos AG. Smoking policy and prevalence in Greece: an overview. Eur J Public Health. 2007;17:211-3.

9. Linardakis M, Sarri K, Bervanaki F, Markatzi I, Hatzis C, Flouri $\mathrm{S}$, et al. Ten-year evaluation of the initiation of a health education program in the schools of Crete. Paediatriki. 2003;66:436-47. (in Greek).

10. Kokkevi A, Terzidou M, Politikou K, Stefanis C. Substance use among high school students in Greece: outburst of illicit drug use in a society under change. Drug Alcohol Depend. 2000;58:181-8.

11. Sichletidis LT, Chloros D, Tsiotsios I, Kottakis I, Kaiafa O, Kaouri S, et al. High prevalence of smoking in Northern Greece. Prim Care Respir J. 2006;15:81-3.

12. University of Patras: Education. http://www.upatras.gr (2009). Accessed 21 May 2009

13. Mammas IN, Bertsias GK, Linardakis M, Tzanakis NE, Labadarios DN, Kafatos AG. Cigarette smoking, alcohol consumption, and serum lipid profile among medical students in Greece. Eur J Public Health. 2003;13:278-82.
14. Steptoe A, Wardle J, Cui W, et al. Trends in Smoking, Diet, Physical Exercise and Attitudes toward Health in European University Students from 13 Countries, 1990-2000. Prev Med. 2002;35:97-104.

15. Xiang H, Wang Z, Stallones L, Yu S, Gimbel HW, Yang P. Cigarette smoking among medical college students in Wuhan, People's Republic of China. Prev Med. 1999;29:210-5.

16. Zhu T, Feng B, Wong S, Choi W, Zhu SH. A comparison of smoking behaviors among medical and other college students in China. Health Promot Int. 2004;19:189-96.

17. Yang G, Fan L, Tan J, et al. Smoking in China: findings of the 1996 National Prevalence Survey. JAMA. 1999;282:1247-53.

18. Vakeflliu Y, Argjiri D, Peposhi I, Agron S, Melani AS. Tobacco smoking habits, beliefs, and attitudes among Medical Students in Tirana, Albania. Prev Med. 2002;34:370-3.

19. Akvardar Y, Demiral Y, Ergör G, Ergör A, Bilici M, Özer OA. Substance use in a sample of Turkish medical students. Drug Alcohol Depend. 2003;72:117-21.

20. Senol Y, Donmez L, Turkay M, Aktekin M. The incidence of smoking and risk factors for smoking initiation in medical faculty students: cohort study. BMC Public Health. 2006;6:128.

21. Kokkevi A, Stefanis C. The epidemiology of licit and illicit substance use among high school students in Greece. Am J Public Health. 1991;81:48-52.

22. Livaditis M, Samakouri M, Kafalis G, Tellidou C, Tzavaras N. Sociodemographic and psychological characteristics associated with smoking among Greek medical students. Eur Addict Res. 2001;7(1):24-31.

23. Lionis C, Wynn-Jones J. Establishing academic rural practice: a future and challenging target. Rural Remote Health. 2007;7:727.

24. Newman IM, Ward JM. The influence of parental attitude and behavior on early adolescent cigarette smoking. J Sch Health. 1989;59:150-2.

25. Papathanasiou G, Georgakopoulos D, Georgoudis G, Spyropoulos P, Perrea D, Evangelou A. Effects of chronic smoking on exercise tolerance and on heart rate-systolic blood pressure product in young healthy adults. Eur J Cardiovasc Prev Rehabil. 2007; 14(5):646-52.

26. Baska T, Straka S, Mad'ar R. Smoking habits in university students in Slovakia. Cent Eur J Public Health. 2000;8:245-8.

27. Jarvis MJ, Wardle J, Waller J, Owen L. Prevalence of hardcore smoking in England, and associated attitudes and beliefs: cross sectional study. BMJ. 2003;326:1061.

28. Schaap MM, van Agt HME, Kunst AE. Identification of socioeconomic groups at increased risk for smoking in European countries: looking beyond educational level. Nicotine Tob Res. 2008;10(2):359-69. 